\title{
Report on Federation of Materials Societies Workshop on Electronic Materials
}

\author{
Fred W. Young, Jr."
}

A workshop on "Electronic Materials: A Key to U.S. Competitiveness?," sponsored by the Federation of Materials Societies, was held in Washington, DC, February 2627, 1986. G. W. Cullen, R. A. Laudise, and D. Richman organized the workshop. Some 125 attendees from government, industry and universities heard a series of talks addressing aspects of electronic materials, ranging from review of the development of electronic materials over the past 50 years to discussions of U.S. government initiatives in materials science and technology and what is required to compete in electronic materials research. All aspects of materials associated with electronic materials science and technology were considered. A recurring theme of the presentations was that the U.S. is losing its preeminence in electronic materials and associated technology

The second day of the workshop was devoted to working sessions to address three questions: (1) Why are electronic materials a key to U.S. competitiveness? (2) What is the present position of U.S. electronic materials technology? (3) What can we do in the U.S. to maintain (regain) our competitive position in electronic materials technology? All attendees participated in one or more of these working sessions. A capsule summary of the deliberations on these three questions might be stated as follows:

The importance of communication technology, of computers, and of instruments and controls technology, all of which are based on electronic materials, is obvious throughout industry and for defense. The U.S. must maintain preeminence in elec- tronic materials. Whereas the U.S. was the principal source of both science and technology in this area, we are rapidly losing our preeminence, particularly in the technology. The question of what we can do to maintain (regain) our preeminence evoked much discussion, and many suggestions were made for actions that universities, industry, government and scientific societies could take that would improve our position. Obviously, there is no simple answer to this last question and the discussion resulted in a long list of possibilities.

A full report on the workshop is being prepared and will be published by the Federation of Materials Societies.

-Fred W. Young, Jr. of Oak Ridge National Lahoratory is chairman of of the MRS External Affairs Committee and is an MRS Councillor.

\section{AIP Holds Annual Symposium for Society Officers}

The American Institute of Physics (AIP) held its annual symposium for officers of member and affiliated societies on March 13 and 14 in Woodbury, New York. MRS was represented at this year's AIP symposium by past president Elton $\mathrm{N}$. Kaufmann. General interest presentations covered manpower trends in science and engineering, the potential effect of current tax reform legislation on retirement plans (particularly from universities), options for membership cards and meeting operations services, and automation of accounting services provided by AIP.

The overall theme of the symposium was electronic publishing and information services. Of particular interest was the new "Pi-NET" service offered by AIP. This communications network will include announcements of job opportunities; meetings information (registration, programs, and abstract submission); advance abstracts and titles from journals; on-line ordering of publications; news; and eventually telemail connections to other data sources such as airline guides and to other networks such as BITNET, which some universities currently use. Not all services will be available in all cases, particularly in the beginning because much depends on how frequently cooperating societies utilize the system and supply information to the data base.

Pi-NET is being offered free for the first year (beginning March 31) to members of all AIP member and affiliated societies and is thus available to MRS members, ac- cording to Lawrence T. Merrill of AIP. It uses the GTE-telenet network and a local network system at AIP. The AIP system has a Datapoint minicomputer with a $30 \mathrm{MB}$ hard disk and ports for four simult aneous users.

Also of significance for publishing and data storage were the presentations on optical disk technology and its impact on information storage and retrieval. Charles Goldstein of the National Library of Medicine gave a fascinating account of a variety of high-storage-density devices that will utilize tens of gigabytes on single optical disks or ribbons. The ribbons are the most useful for archival purposes where random access is unnecessary. (One can picture an entire library stored in a jukebox-sized cabinet.) Because the optical disks are also computer readable, interlibrary loans could be executed in minutes from a terminal generating complete books on high-speed laser printers. The analogy to the revolutions accompanying the transition from paper tape and cards to magnetic tape, then to magnetic floppy disks and Winchester hard disks cannot be missed.

While optical disks are revolutionizing the storage and retrieval end of the publishing chain, the production end is also being revolutionized by high-speed, highquality laser printers and the increasing use of computer-based composition. Carol Risher of the Association of American Publishers discussed a new provisional standard for electronic manuscripts which would serve the technical publishing community. The standard is intended to allow any manuscript to be processed on any computer and to enable storing the manuscripts on searchable data bases from which paper or electronic books can be produced. All special characters, symbols and tabular representations would be coded using only ASCII characters. If this standard is to succeed, software will need to be readily available for converting present wordprocessed files to the new standard format.

Paste-up or page layout, although still largely done manually, is also succumbing to au tomation. Milton B. Carter of Seybold Associates showed how a great deal of page make-up and pagination can be computerized and how intelligent programs allow for human interaction to make close-call decisions, a capability not previously available with the batch-processing philosophy of older programs. Advances in display terminals and in high-speed laser printers now let the operator see a very accurate facsimile of the page as it will appear in print. Carter noted that this capability is significant enough to deserve its own mnemonic-wysiwyg. Pronounced "wiseewig," it stands for "what you see is what you get."

For further information about any of these speakers or topics contact American Institute of Physics, 335 East 45th Street, New York, NY 10017; telephone (212) 661-9404 


\section{AIP INTRODUCES PI-NET}

\section{AN ELECTRONIC PHYSICS INFORMATION NETWORK}

\section{MAKE A LOCAL PHONE CALL... THE RESTISON US! Pi-NET is}

an Electronic Database Service providing selected AIP and Member Society Information to the Physics Community, Online. This one-year Pilot Program is being offered Free Of Charge (except for the cost of a local phone call) to Members of AIP Member and Affiliate Societies.

\section{Services Include}

$\square$ Job Opportunities in physics

$\square$ Calendar of Meetings

$\square$ Advance Abstracts of over 40 AIP and Member Society journals

$\square$ Journal Article Titles from AIP's SPIN database including: author(s), date, page numbers

$\square$ Electronic catalog and online ordering of AIP and Member Society publications

$\square$ Announcements and News Releases

\section{Try it Today From Your Own PC!}

1. Dial local GTE Telenet number.

(To obtain local number, call 1-800-336-0437; in Virginia call 703-689-6400)

2. When you hear the high-pitched tone, press $\langle$ ENTER $>$ twice.

3. Telenet will announce itself and display TERMINAL $=$. Type in D1 and press $\langle$ ENTER $\rangle$.

4. At the @ prompt, type in $\mathbf{5 1 6 6 1 7}$ and press 〈ENTER〉. Telenet will display 516617 CONNECTED; press 〈ENTER> again.

5. Pi-NET will announce itself. To register, type in an asterisk $\langle *\rangle$ and press $\langle$ ENTER $\rangle$.

6. Follow instructions displayed.
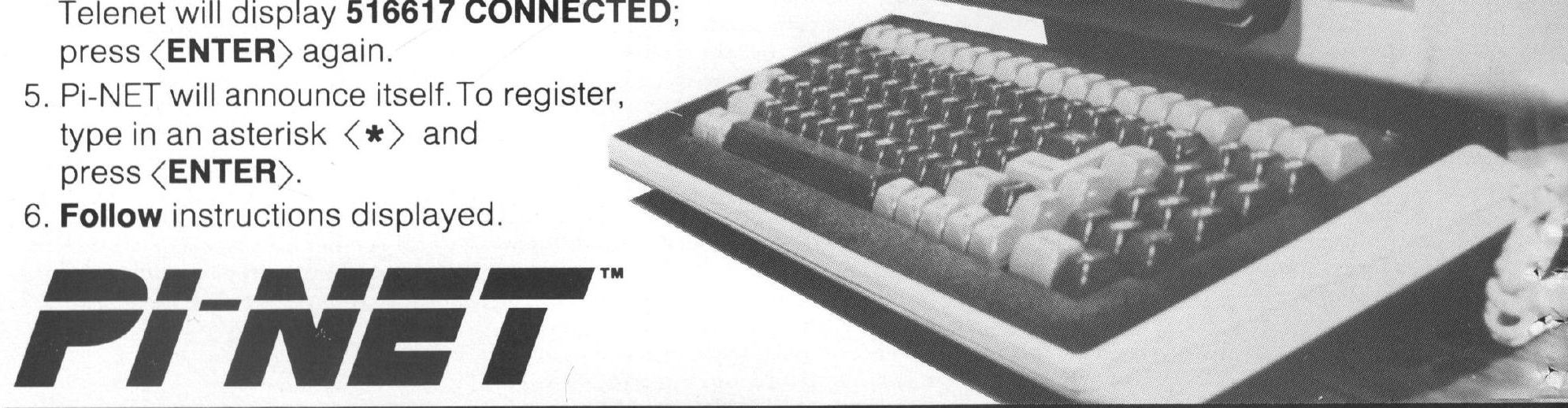